\title{
Behavioural manifestations of third ventricular colloid cysts
}

\author{
JEFFREY M LOBOSKY, ${ }^{*}$ JOHN C VANGILDER, ${ }^{*}$ ANTONIO R DAMASIO $\dagger$ \\ From the Department of Surgery (Division of Neurosurgery*), and Department of Neurology (Division of \\ Behavioural Neurology†), The University of Iowa College of Medicine, Iowa City, Iowa, USA
}

SUMMARY Three patients with third ventricular colloid cysts manifested disturbances of memory, emotion and personality in the absence of hydrocephalus. All three patients demonstrated significant improvement following removal of the tumours. The symptoms and signs associated with these neoplasms may be attributed to compression or vascular compromise of the diencephalon with disorder of major limbic system structures. Tumour removal should be undertaken in patients with symptoms even in the absence of hydrocephalus, and ventricular shunting may be inadequate as a sole therapeutic measure.

Colloid cysts of the third ventricle are uncommon, comprising less than $1 \%$ of intracranial neoplasms. Initially described by Wallmann' in 1858 , they remained no more than a pathologic curiosity until Dandy' $s^{2}$ first successful operative removal of this tumour in 1921. These midline masses are benign and lend themselves to complete removal with minimal morbidity and mortality utilising microscopic surgical techniques.

Colloid tumours afflict males and females with equal frequency. They have been reported between the age extremes of 2 months and 79 years but most become symptomatic between the third and fifth decades of life. The cysts range in size from 0.3 to 9 $\mathrm{cm}$ but the majority are found to be between 1 and 3 $\mathrm{cm}$ in diameter. Sjövall ${ }^{3}$ initially postulated the paraphysis as the site of origin of these tumours but this theory was later challenged by Kappers. ${ }^{4}$ Shuangshoti ${ }^{5}$ subsequently suggested that the cysts arise from infolding of the neuroepithelium which lines the ventricular cavities thus accounting for their occurrence in areas other than the anterior third ventricle. Most neuropathologists concur with this latter theory of pathogenesis.

The symptomatology of colloid cysts is protean and the classical history of positional headache with intermittent apoplectic episodes is rare. Nonethe-

Address for reprint requests: Jeffrey M Lobosky, MD, Division of Neurosurgery, The University of Iowa Hospitals and Clinics, Iowa City, Iowa 52242, USA.

Received 31 January 1984

Accepted 10 March 1984 less, headache is the most consistent complaint and is usually related to accompanying hydrocephalus. Venous distention secondary to compression of the deep cerebral veins or their tributaries has also been postulated as a contributing cause of the cephalgia. ${ }^{07}$

Less attention has been focused upon the abnormal behavioural manifestations of this disorder and early authors ${ }^{x-11}$ considered the neuropsychological disturbances to be a reflection of ventricular dilatation. Others ${ }^{4} 11^{12-14}$ have noted a similarity between the mental decline in patients with colloid cysts and in those with normal pressure hydrocephalus. Thus, a causative relationship between the two has become accepted. The alternative possibility of diencephalic dysfunction from the tumour has been largely ignored.

Yenerman, ${ }^{14}$ in his review of 54 patients with neuroepithelial cysts, agreed that hydrocephalus was the most likely cause for the frequently observed dementia. He and others $8 \times 14$ added, however, that pressure effects from the tumour on diencephalic structures might play a significant aetiologic role. In this report we describe three patients with colloid cysts of the third ventricle whose findings may help elucidate the role of diencephalic dysfunction in the generation of abnormal behavioural symptoms.

\section{Case reports}

Case 1

In June, 1980, a 64-year-old housewife was investigated for a 3 year history of progressive gait difficulty and uri- 


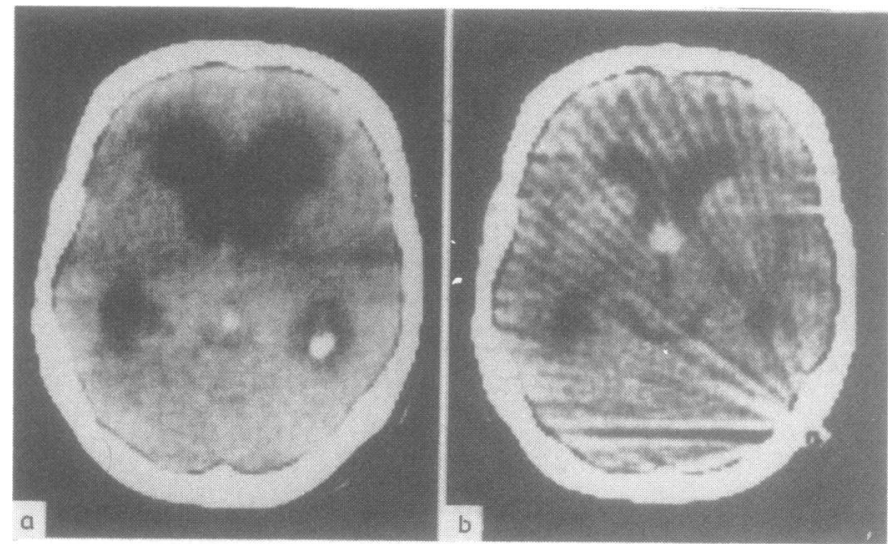

Fig 1 (Case 1) A. Initial contrast enhanced CT scan revealing hydrocephalus. The level of this scan is above the third ventricle and the tumour is not identified. B. Repeat CT scan 10 months after insertion of ventriculocaval shunt demonstrating resolving hydrocephlus and a colloid cyst.

nary incontinence. Neurological examination revealed severe dementia with marked disturbances of memory, intellect and orientation associated with confabulations. There was a generalised increase in muscle tone, hyperactive muscle stretch reflexes, bilateral extensor plantar responses, an apractic gait and frontal lobe release signs including snout, grasp and glabellar reflexes. Neuropsychologic evaluation revealed severe impairment of all cognitive functions. Verbal and performance IQs were measured at 62 and $<50$ respectively, and memory quotient was placed at 55. A computed tomographic scan (fig 1a) showed marked hydrocephalus but an enhancing third ventricular mass was not appreciated. The patient underwent intracranial pressure monitoring which revealed both plateau and beta pressure waves greater than $25 \mathrm{~mm} \mathrm{Hg}$ and a right ventriculocaval shunt was inserted, following which the patient was discharged. In April, 1981, the patient was reevaluated. Her apractic gait and urinary incontinence had resolved and she no longer demonstrated long tract signs or frontal release phenomena. Her dementia, however, had progressed to such a degree that she required institutionalisation. The patient was markedly confused and oriented only to her name. She was unable to recall even a single object one minute after its presentation and she had lost all ability to calculate and reason. Formal psychometric evaluation could not even be obtained. A second CT scan (fig 1b) demonstrated improvement of the hydrocephalus and a prominent third ventricular mass which was apparent both on the enhanced and unenhanced studies. Retrospective review of the 1980 scan revealed the mass to have been present at that time. A colloid cyst estimated to be slightly greater than $2.0 \mathrm{~cm}$ in diameter was removed through a right frontal transventricular operation. By the third post-operative day her mental status had improved dramatically and she was oriented to place, person and time with appropriate simple conversation. Neuropsychological testing 16 months after surgery revealed improvement in language and visuospatial abilities. The verbal IQ was 70, performance IQ 68 and her memory quotient was 66 . Currently she is at home and is maintaining an efficient household.

This patient exemplifies persistence of dementia after treatment of her hydrocephalus and indicates the possibility of an alternative aetiology. The improvement of her cognitive abilities after tumour removal suggests that diencephalic dysfunction could have been the cause of her behavioural disorder and underscores the inadequacy of ventricular shunting as a sole therapeutic procedure in such cases.

\section{Case 2}

This 33-year-old insurance salesman was referred to University Hospitals in May, 1982 with an 8 year history of intermittent "anxiety attacks." These episodes were characterised by severe agitation, chest pain, diaphoresis, tachypnoea, tachycardia and a sense of impending doom. These attacks had increased both in their frequency and severity, occurring up to 10 times daily and lasting from a few seconds to several minutes with no associated abnormal motor movements or loss of consciousness. The patient underwent prolonged psychiatric treatment without improvement. On occasion headaches accompanied these episodes but no other physical or neurological complaints were noted. The patient had a CT scan performed which demonstrated a $2.0 \mathrm{~cm}$ mass in the anterior third ventricle without hydrocephalus. Because of the lack of ventriculomegaly, this was interpreted as an asymptomatic colloid cyst. The patient's general and neurological examinations were normal except for atrophy of the right calf secondary to childhood poliomyelitis. An electroencephalogram showed a non-specific right temporal dysrhythmia and a normal neuropsychological profile. A second CT scan (fig 2 ) revealed the contrast enhancing, 2.0 $\mathrm{cm}$ mass in the anterior third ventricle without hydro- 


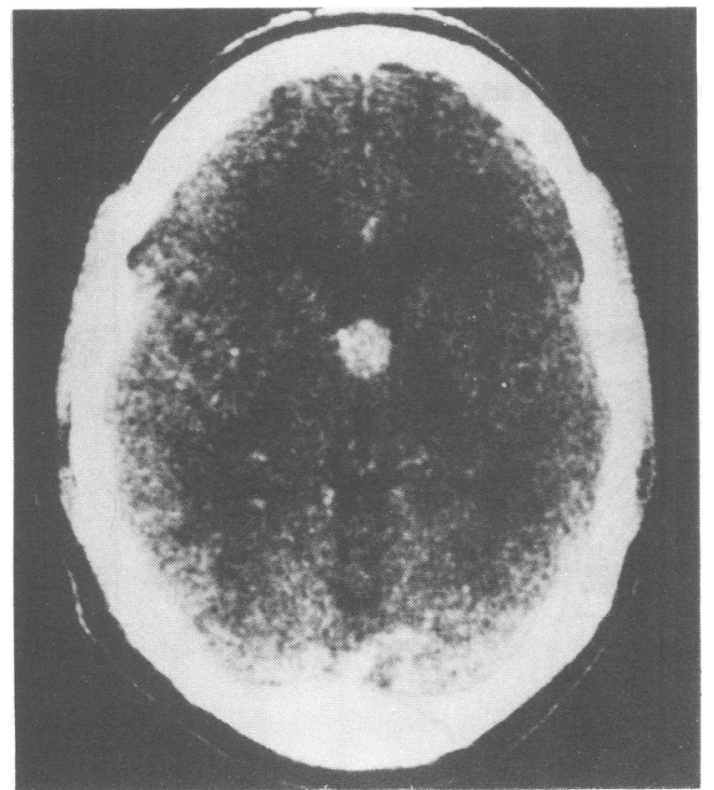

Fig 2 (Case 2) Enhanced CT scan with an anterior third ventricular colloid cyst. There is no evidence of significant ventricular enlargement.

cephalus. The patient underwent a right frontal craniotomy and a transcallosal removal of the colloid tumour. His postoperative course was complicated by 3 days of mutism and several tonic-clonic seizures, the latter which were controlled with dilantin. After the mutism resolved the patient had impaired memory for recent events, but this rapidly cleared. Follow up at 10 months after removal of the tumour demonstrated no further "anxiety' episodes or memory difficulties. He remains gainfully employed at his previous occupation and has had no further convulsions.

\section{Case 3}

This 28-year-old female heavy equipment operator was referred to University Hospitals in September, 1981 with a 2 year history of progressive paranoid ideation, depression. social withdrawal and impaired memory. She had been under the care of a psychiatrist but had no improvement following treatment with several psychotropic medications A previous computed tomographic scan revealed a third ventricular mass which was interpreted as an asymptomatic colloid cyst since there was no attendant hydrocephalus. Because she was refractory to psychiatric therapy her antipsychotic medications were discontinued and she was referred to us to evaluate the relevance of the tumour to the pathogenesis of her behavioural symptoms. Her general physical and neurological examinations were normal except for her mental status. She had a bland affect and an impairment of recent memory. Neuropsychological testing revealed a verbal and performance IQ (93 and 95 respectively) and her memory quotient was 82 . An MMPI profile was indicative of a personality disorder and consistent with

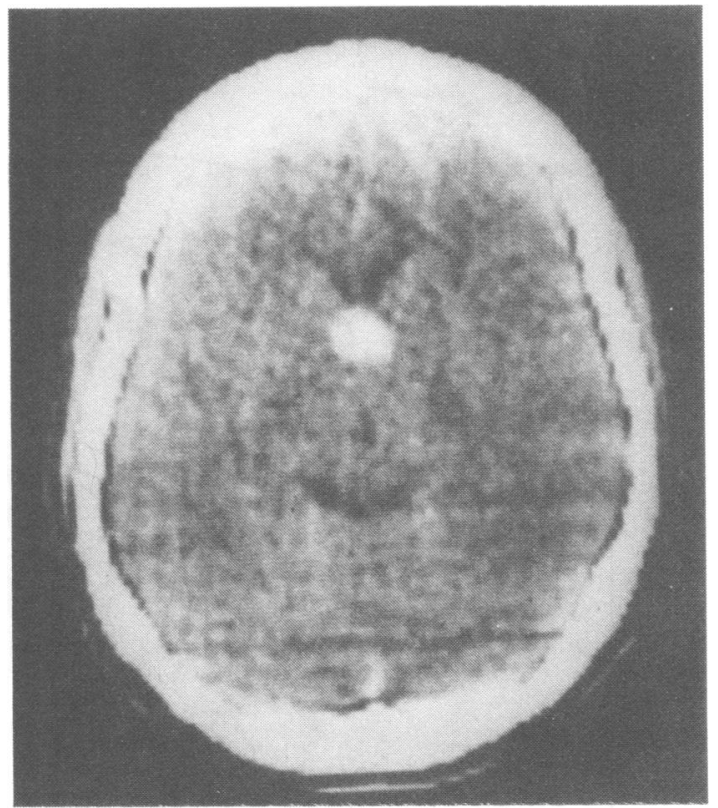

Fig 3 (Case 3) CT scan after contrast infusion showing an anterior third ventricular mass without associated hydrocephalus.

paranoid schizophrenia. A second CT scan (fig 3) showed persistence of the third ventricular tumour without hydrocephalus. By a right transventricular operation a neuroepithelial cyst estmated at $2.0 \mathrm{~cm}$ in diameter was extirpated without difficulty. Her immediate postoperative course was complicated by a transient worsening of her recall but this rapidly resolved. She was discharged home and remained free of paranoia and depression for 12 months without medication. Evaluations 6 months after surgery failed to elicit intellectual or memory deficits by clinical examination. A second neuropsychological evaluation substantiated modest improvement in her verbal (102) and performance (98) IQ scores. Memory quotient remained unchanged at 83 and her MMPI profile, although still reflecting schizophrenic features was far less abnormal than before.

In October, 1982 this patient returned with paranoid ideation and hallucinations. However. her intellect and memory remained unchanged and she was again placed on psychotropic medications. A CT scan showed neither tumour recurrence nor hydrocephalus.

\section{Discussion}

In the three patients, the initial presentation and the remission of behavioural symptoms after surgical removal of the tumours support the notion that colloid cysts located in the anterior third ventricle are causally associated with marked neuropsychological disorder in the absence of hydrocephalus. This is not 


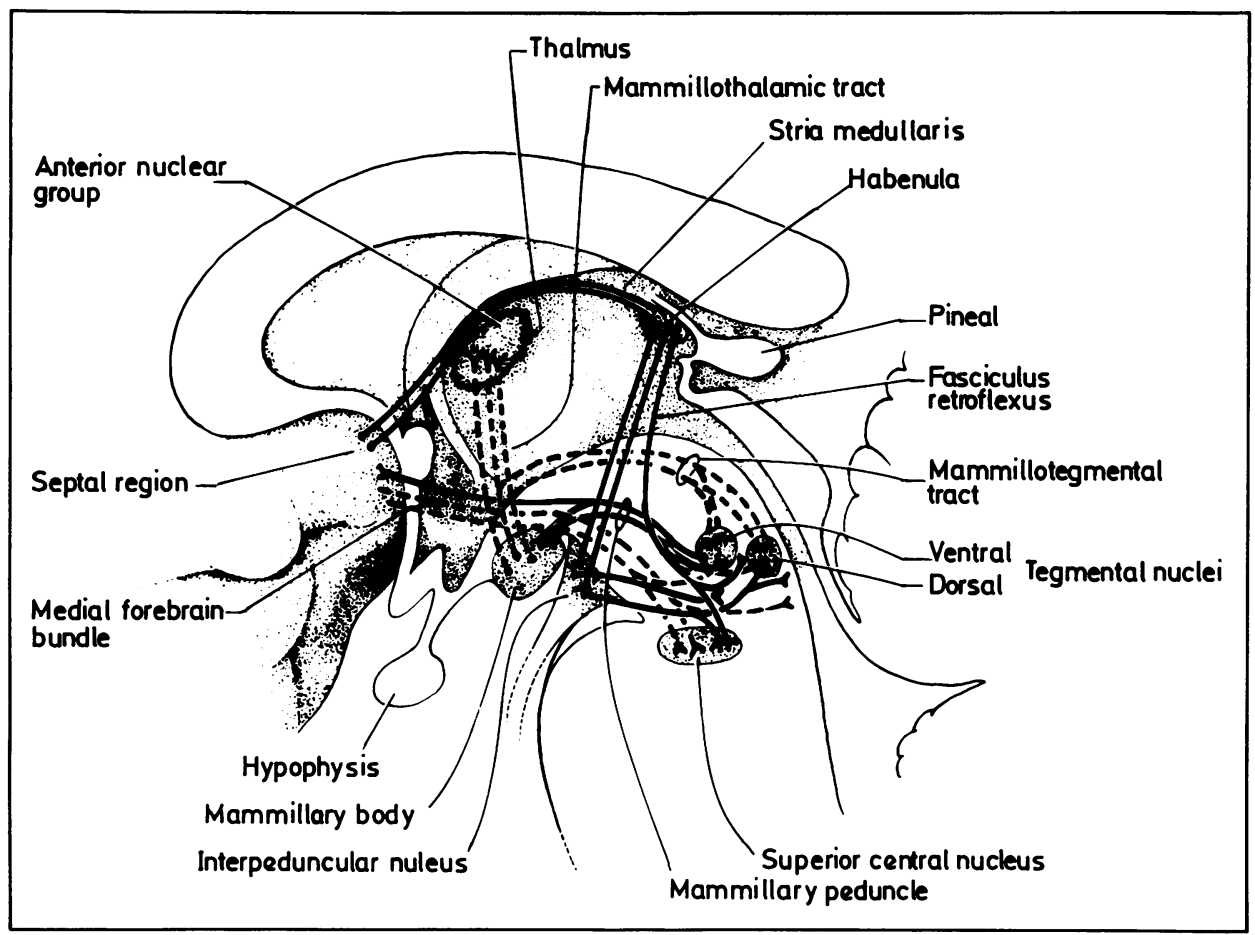

Fig 4 Schematic view illustrating major interconnections between the hypothalamus, brainstem and diencephalon.

a new concept but it has received little attention in the literature.

The neuropathological basis for the behavioural disturbances associated with colloid cysts may be secondary to dysfunction of the diencephalic structures. Papez, ${ }^{15}$ in 1937, first theorised that the mesial brain structures, later known as the limbic lobe, were primarily responsible for the generation and regulation of emotion. MacLean ${ }^{16}$ and Yakovlev ${ }^{17}$ further elaborated this idea and the concept of a limbic system, encompassing the limbic cortices, subcortical regions and their diverse interconnections evolved.

The limbic system is an intricate network of interrelated structures. At the cortical level it comprises the mesocortices which include the cingulate gyrus, the hippocampal formation, and the parahippocampal and retrosplenial cortices. Multiple pathways, such as the fimbria-fornices, the stria terminalis, and the uncinate fasciculus, connect these structures with important subcortical limbic regions (for example the septal and accumbens nuclei, the substantia innominata, the amygdaloid nuclei, the hypothalamus, the anterior and dorsomedial thalamic nuclei) while direct projections reconnect them to the surrounding cortex, and, indirectly, to the multimodal sensory regions. ${ }^{18-22}$ Disturbance of these structures, either by direct compression or vascular compromise, may explain the symptoms manifested by our patients. As illustrated in fig 4, masses in the anterior third ventricle place several limbic system structures at risk.

Significant memory impairment was present in our first patient. This could have resulted from: (a) dysfunction of the mammillothalamic tract or of its terminal structure, the anterior nucleus of the thalamus, (b) dysfunction of the septal region or the dorsomedial nucleus of the thalamus, (c) dysfunction in medial temporal regions, mediated remotely by a disturbance in (b).

Burkle and Lipowski ${ }^{23}$ reported a patient with a colloid cyst who presented with psychiatric symptoms and amnesia. They noted her memory disorder was more severe than could have been anticipated on the basis of either her hydrocephalus or psychiatric illness alone, and suggested that dience- 
phalic compromise contributed significantly to the amnesia. Delay ${ }^{24} 25$ documented the association between a Korsakoff-like syndrome and pathologic changes in the mammillary bodies and mammillothalamic tracts. Kahn and Crosby ${ }^{26}$ described five patients with craniopharyngiomas displacing the anterior third ventricle whose memory deficits improved after surgery. Memory loss has also been attributed to lesions of the dorsomedial thalamic nucleus by Victor, ${ }^{27}$ McEntee, ${ }^{2 \times}$ and more recently by Squire. ${ }^{24}$ Lindquist and Norlen $^{30}$ found a Korsakoff-like syndrome in patients with ruptured anterior communicating artery aneurysms and suggested that damage to the septal region could account for the amnesia. Recently Damasio et al $^{3+}$ have studied patients with similar memory abnormalities in whom computed tomography confirmed damage to the basal forebrain area. Dysfunction in the periventricular limbic areas can cause changes in affect and emotion either directly or by remote effect in the inter-connected cingulate cortex. ${ }^{32-34}$ Lesions of the cingulate are associated with disturbed emotional expression and affect. ${ }^{33}$

The anxiety episodes experienced by our second patient could have had their origin in diencephalic structures. Attendant to his sense of impending doom were tachypnoea, tachycardia and diaphoresis, suggesting an autonomic disturbance. The principal known interconnections between the hypothalamus and the remainder of the diencephalon and lower brainstem structures are illustrated in figure 4 . Compromise of these pathways, which include the fasciculus retroflexus, mammillotegmental tract, mammillary peduncle and medial forebrain bundle, may manifest itself as autonomic dysfunction. Furthermore, the cyst may have served as an irritative focus for "autonomic seizures."

The patient who presented with memory impairment and paranoid schizophrenia poses a more complex problem. The pathogenesis of schizophrenia still awaits elucidation. It is plausible that dysfunction in areas of the limbic system is associated with psychotic manifestations and the initial 12 month remission of her symptoms was encouraging. However, her recent relapse of paranoia and hallucinations without impairment of memory or intellect suggests that the two disease processes are independent and thus we cannot support removing the tumours on the basis of psychosis alone.

It is important that physicians evaluating patients with colloid cysts recognise that abnormal behavioural manifestations may be the result of diencephalic compression. The lack of ventricular dilatation does not exonerate the tumour as the cause of these symptoms. Furthermore, as demonstrated by case 1 , ventricular shunting may be inadequate as a sole therapeutic measure.

We thank Ms Carolyn Lewis for her assistance in the preparation of this manuscript and Mr Tom Weinzerl for his illustrations.

This work was supported in part by NINCDS Grant PO1 NS 19632-01.

\section{References}

' Wallmann H. Eine colloidcyste im dritten Hirnventrikl und ein Lipom im Plexus Coroides. Virchow Arch 1858; $11: 385-8$.

2 Dandy WE. Diagnosis, localization and removal of tumors of the third ventricle. Bull Johns Hopkins Hospital 1922;33: 188-9.

${ }^{3}$ Stövall E. Über eine Ependymcyste embryonal Charakters (Paraphyse) im dritten Hirnventrikel mit tödlichen Ausgang. Beitr Path Anat 1909;47:248-68

${ }^{4}$ Kappers JA. The development of the paraphysis cerebri in man with comments on its relationship to the intercolumnar tubercle and its significance for the origin of cystic tumors in the third ventricle. J Comp Neurol 1955; 102:425-510.

shuangshoti S, Roberts MP. Netsky MG. Neuroepithelial (colloid) cysts. Arch Path 1965;80:214-24.

- Brun A. Egund N. The pathogenesis of cerebral symptoms in colloid cysts of the third ventricle: A clinical and pathoanatomical study. Acta Neurol Scand 1973;49:525-35.

7 Stookey B. Intermittent obstruction of the Foramen of Monro by neuroepithelial cysts of the third ventricle. Bull Neurol Institute NY 1934:3:446.

" Cairns H, Mosberg WH. Colloid cyst of the third ventricle. Surg Gynecol Obstet 1951;92:545-70.

${ }^{4}$ Kelly R. Colloid cysts of the third ventricle. Analysis of twenty nine cases. Brain 1951;74:23-65.

${ }^{10}$ Riddoch G. Progressive dementia, without headache or changes in the optic discs, from tumours of the third ventricle. Brain 1936;59:225-33.

"Zeitlin H, Lichtenstein BW. Paraphysical cysts of the third ventricle. J Nerv Ment Dis 1940;91:704-11.

12 Little JR, MacCarty CS. Colloid cysts of the third ventricle. J Neurosurg 1974;39:230-5.

${ }^{13}$ Ojemann RG. Normal Pressure Hydrocephalus. Clinical Neurosurg 1971;18:337-70.

14 Yenerman MH, Bowerman CI. Haymaker W. Colloid cysts of the third ventricle: A clinical study of 54 cases in the light of previous publications. Acta Neurosurg 1958; 17:211-77.

15 Papez JW. A proposed mechanism of emotion. Arch Neurol Psychiat 1937;38:725-43.

${ }^{10}$ MacLean PD. Psychosomatic disease and the "visceral brain": recent developments bearing on the Papez theory of emotion. Psychosomatic Medicine 1949; 11:338-53.

17 Yakovlev PI. A proposed definition of the limbic system. In: Hockman CH, ed. Limbic System Mechanisms and Anatomic Function. Springfield: CC Thomas, 1969.

" Pandya DN, VanHoesen GW, Mesulam MM. The 
cortico-cortical projections of the cingulate cortex in the rhesus monkey. Exp Brain Res 1981;42:319-30.

${ }^{19}$ VanHoesen GW, Pandya DN. Some connections of the entorhinal (area 28) and perirhinal (area 35) cortices of the rhesus monkey. I Temporal lobe afferents. Brain Res 1975;95:1-24.

20 VanHoesen GW, Pandya DN. Some connections of the entorhinal (area 28) and perirhinal (area 35) cortices of the rhesus monkey. III. Efferent connections. Brain Res 1975;95:39-59.

${ }^{21}$ VanHoesen GW, Pandya DN, Butters N. Cortical afferents to the entorhinal cortex of the rhesus monkey. Science 1972;175:1471-3.

22 VanHoesen GW, Pandya DN, Butters N. Some connections of the entorhinal (area 28) and perirhinal (area 35) cortices of the rhesus monkey. Il. Frontal lobe afferents. Brain Res 1975;95:25-38.

${ }^{23}$ Burkle RM, Lipowski ZJ. Colloid cyst of the third ventricle presenting as psychiatric disorder. Am J Psychiatry 1978;135:373-4.

${ }^{24}$ Delay J, Brian S. Syndrome de Korsakoff et corpus mammillaires. Encéphale 1958;47:99-142.

${ }^{25}$ Delay J, Brian S, Derouesne C. Syndrome de Korsakoff et etioligie tumorale. Rev Neurol (Paris) 1964; 111:97-133.

${ }^{26}$ Kahn EA, Crosby EC. Korsakoff s syndrome associated with surgical lesions involving the mammillary bodies. Neurology (Minneap) 1972;22:117-25.
${ }^{27}$ Victor M, Adams RD, Collins GH. The WernickeKorsakoff Syndrome. Philadelphia: Davis, 1971.

${ }^{28}$ McEntee WJ, Biber MP, Perl DP, et al. Diencephalic amnesia: A reappraisal. J Neurol Neurosurg Psychiatry 1976;39:436-41.

${ }^{24}$ Squire LR, Moore RY. Dorsal thalamic lesion in a noted case of human memory dysfunction. Ann Neurol 1979; 6: 503-6.

${ }^{30}$ Lindquist G, Norlen G. Korsakoff's syndrome after operation on ruptured aneurysms of the anterior communicating artery. Acta Psychiat Scand 1966; 42: $24-34$

${ }^{31}$ Damasio AR, Graff-Radford $\mathrm{N}$, Eslinger $\mathrm{P}$, et al. Amnesia following basal forebrain lesions. Arch Neurol (in press).

${ }^{32}$ Damasio AR. The Frontal Lobes. In: Heilman K, Valenstein E, eds. Clinical Neuropsychology, ed 2. New York: Oxford University Press, 1983.

${ }^{33}$ Damasio AR, VanHoesen GW. Emotional disturbances associated with focal lesions of the frontal lobe. In: Heilman K, Satz P, eds. The Neurophysiology of Human Emotion: Recent Advances. New York: The Guilford Press, 1983.

${ }^{34}$ Taren JA. Anatomical pathways related to the clinical findings in aneurysms of the anterior communicating artery. J Neurol Neurosurg Psychiatry 1965;28:22834. 